\title{
CLAUDE LEFORT Y LOS REGÍMENES DE LA POLÍTICA EN LAS AMÉRICAS ${ }^{1}$
}

\begin{abstract}
Martín Plot ${ }^{2}$
Abstract: Since the transitions to democracy of the eighties, two trends of post-Marxist thought had dominated the debates in the region. On the one hand, that of a reading of Gramsci that was split between a more conventional, social-democratic version and a poststructuralist, self-proclaimed radical one. On the other hand, there was also a quite influential trend: a phenomenological one that relied on the anti-totalitarian theorizations of authors such as Hannah Arendt and Claude Lefort. The fellow travelling of these two parallel theoretical and political projects came to an end, however, with the Schmittian turn given by some of the authors associated to the label of radical democracy. This paper will conclude with a critique of this "turn". Before that, however, a summary and reformulation of Claude Lefort's notions of forms of society and regimes will be offered as a general framework for the reconsideration of these debates.
\end{abstract}

Keywords: Claude Lefort - post-Marxism - Carl Schmitt - democracy.

\section{Introducción}

Comenzaré simplemente asumiendo que el entrelazamiento de los procesos de transición a la democracia en América Latina con el abandono del horizonte de la violencia revolucionaria en la izquierda política fue de una relevancia difícil de equiparar por otros factores que, de todos modos, también contribuyeron a la estabilización de la vida política democrática en la región. Durante ese período, dos tradiciones de pensamiento postmarxista dominaron el giro democrático de la izquierda tanto teórica como política. Por un lado, la de un gramscianismo, que, a su vez, se caracterizaba por tener dos vertientes: una encabezada por la reformulación post-estructuralista que Ernesto Laclau y Chantal Mouffe hicieran del pensamiento de Gramsci en Hegemonía y estrategia socialista y otra, más dispersa, de intelectuales y actores políticos que abrazaban decididamente la historia y el proyecto de la socialdemocracia europea. Por otro lado, también tuvo fuerte impacto en la región el pensamiento fenomenológico o post-fenomenológico, en el que autores como Hannah

\footnotetext{
${ }^{1}$ Dossiê Claude Lefort: esse texto é parte do dossiê publicado a partir das comunicações realizadas no Colóquio Internacional Claude Lefort: a invenção democrática hoje, realizado na Universidade de São Paulo entre os dias 13 e 16 de outubro de 2015.

${ }^{2}$ Investigador independiente del Conicet y Profesor titular del Idaes-UNSAM.
} 
Arendt o Claude Lefort, críticos centrales del totalitarismo, incluso en sus vertientes "izquierdistas", contribuyeron a la reformulación del proyecto democrático, haciéndolo esta vez en un abierto rechazo de la tradición revolucionaria leninista o foquista, sin por ello abandonar las aspiraciones igualitarias del pensamiento tradicionalmente definido como emancipatorio. Autores como Norbert Lechner en Chile, e investigadores como Isidoro Cheresky o Claudia Hilb en Argentina, formaron y forman parte de este linaje.

Ambas tradiciones, globalmente identificadas con lo que dio en llamarse "democracia radical", coexistieron como compañeras de ruta por un largo tiempo. Este paralelismo de proyectos comenzó a resquebrajarse, de todos modos, con el giro schmittiano dado por parte de los autores de la democracia radical durante la última década. Propondré un esbozo de crítica a este giro decisionista o voluntarista de algunos autores y actores de la izquierda latinoamericana al final de este trabajo. Pero para llegar a ello, primero articularé brevemente el estilo de análisis que creo es más característico de la tradición fenomenológica o post-fenomenológica del pensamiento de la izquierda democrática. Una vez ofrecida esta mirada de lo que considero uno de los mayores legados de Claude Lefort, sintetizaré de forma breve y esquemática una reformulación (que ya he desarrollado más extensamente en otros trabajos) de la noción lefortiana de formas de sociedad - reformulación que creo permite reactivar el carácter crítico y analítico presente en la obra de Lefort. Finalmente, cerraré el texto con la mencionada observación acerca del giro decisionista de ciertas izquierdas latinoamericanas.

\section{Una fenomenología de la democracia}

Lefort solía referirse a Alexis de Tocqueville como un fenomenólogo de la democracia, como alguien que realiza "cortes" en la carne de lo social - pero que, a diferencia de los que piensan que un "cuerpo político", una sociedad dada, puede simplemente diseccionarse para conocerla por partes, digamos, sin correr el riesgo de su desmembramiento y por lo tanto de la destrucción de aquello que estamos tratando de comprender, nunca olvidaba que, precisamente en su ser carne, en las sociedades "todo está articulado con todo" y, además, se encuentra en permanente mutación. Desde esta perspectiva, el estudio de formas políticas - nuevas o viejas - supone un constante esfuerzo perceptual e interpretativo que consiste en prestar atención a la aparición de lo nuevo, o de aquellos ordenamientos y a veces aparentemente leves alteraciones que parecen estar esbozando la configuración de algo nuevo.

Una de las formas más notorias en las que una perspectiva fenomenológica o postfenomenológica como la de Lefort permite reconocer nuevas dinámicas e interrelaciones en la vida pública contemporánea es aquella que logra ofrecer una superación y articulación de la dicotomía espacio público (asociado en algunas tradiciones exclusivamente a los 
discursos y acciones de la sociedad civil — algo de lo que Lefort fue explícitamente crítico, pero un poco al pasar) y espacio público-político (relacionado usualmente con "públicos fuertes" como el parlamento o las cortes y con la sociedad política en general). Así, para un estudio fenomenológico de la política, en la relación entre las dinámicas espontáneas y "anárquicas" de la sociedad civil y las formas más institucionalizadas de la sociedad política no hay ruptura sino continuidad y alimentación mutua.

En este contexto, puede decirse, por ejemplo, que el concepto de "influencia" que Jürgen Habermas usó para referirse a la relación entre espacio público e instituciones políticas representativas, ya no describe correctamente (si es que alguna vez lo hizo) la relación entre la formación de opiniones y juicios y su relación con el sistema representativo - el uso que Habermas hizo del término se encuentra excesivamente inspirado en una concepción de exterioridad mutua entre sociedad civil y sociedad política. Una fenomenología política de inspiración lefortiana, por el contrario, se plantea una imbricación entre ambas, una dinámica en la que ni los actores de la sociedad civil ni los actores políticos clásicos son vistos como encarnando positivamente determinadas lógicas de acción - para decirlo en lenguaje habermasiano: rechazando el prejuicio conceptual que supondría que los primeros deberían involucrarse exclusivamente en lógicas de acción comunicativa, mientras que los últimos podrían legítimamente reducir el horizonte de su acción a la lógica instrumental. Es decir, para la perspectiva fenomenológica, tanto el espacio público de la sociedad civil como el espacio público-político participan de la totalidad de la vida instituyente de las democracias contemporáneas - tanto de la "actividad" de la acción y la enunciación como de la "pasividad" de la percepción y el juicio, configurando así una dinámica de acciones percipientes y de percepción activa cuyos significados son múltiples y abiertos.

Acabo de decir "vida instituyente" y lo hice adrede, para así poder insertar aquí una intervención acerca del uso de una categoría clave en Lefort y en su maestro y amigo Maurice Merleau-Ponty. La institución, la pasividad y Las aventuras de la dialéctica fueron el par de trabajos, contemporáneos entre sí, - una el dictado de un curso y la otra una intervención teórico-política en el debate de su tiempo - de Merleau-Ponty en los que este desplegó una crítica - a la que se le trató de dar una formulación filosófica — del voluntarismo decisionista en que había devenido el Marxismo revolucionario luego del fracaso de la ineluctabilidad histórica formulada por las versiones "objetivistas" de la dialéctica. En esta crítica Merleau-Ponty formuló la matriz del lenguaje de "lo instituyente" y "lo instituido" que luego sería desarrollado en direcciones diferentes por Lefort y Cornelius Castoriadis. 
El modo en que esto se inserta aquí en realidad viene de un intercambio una vez establecido con Lucas Martin, ${ }^{3}$ al recordar éste una lectura reciente en la que un intérprete de Lefort sostenía que sus nociones de "la política" y "lo político" podían equipararse a las dimensiones "constituida" y "constituyente" de la vida política respectivamente. Lucas Martin se preguntaba cómo podía ser que Lefort mismo, conocedor sin duda del lenguaje del poder constituyente y poder constituido de la tradición revolucionaria francesa, no hubiese él mismo hecho tal conexión. La razón, en mi opinión, se debe precisamente a que el pensamiento de Lefort es profundamente deudor de la doble crítica merleau-pontyana tanto de las ambiciones constituyentes, ex nibilo de la imaginación revolucionaria como de la visión institucionalista liberal/conservadora que ve en lo constituido - las constituciones, las leyes, los poderes del estado - la capacidad de "contener la vida política"; que quiere decir la capacidad de dar cuenta de ella acabadamente y sin excesos, de tal modo que no hubiera excepciones, imprevistos o acciones extra-institucionales que deban ser contemplados o incluso tolerados.

La fenomenología política democrática, generadora de esta doble complicación la de considerar tanto a las instituciones como flexibles y en mutación como a las acciones deudoras de una sensibilidad por lo dado - está inspirada en una perspectiva que reacciona a la multidimensionalidad de los fenómenos y los acontecimientos políticos esto es, al hecho de que éstos no tienen un único sentido, o un sentido que los agote en su capacidad generadora de sentidos. Esta multidimensionalidad de los fenómenos políticos proviene, en parte, de su aparecer - que es su ser - en un espacio multiperspectivo. Y esta perspectiva interpretativa no supone de ninguna manera el renunciar al ejercicio del juicio o la adopción de una actitud relativista. Muy por el contrario, esta fenomenología política nos obliga a agudizar nuestra atención, a esforzarnos por ampliar nuestra mirada, a "ir de visita" (como diría Arendt, en diálogo con Kant) al lugar de otras perspectivas y de otras opiniones, para así poder ofrecer una visión de conjunto - visión que de todos modos no ignora la existencia de puntos ciegos que nos obligan a nunca dejar de estar atentos a la aparición de lo nuevo, o de nuevas dimensiones de aquello que creíamos haber comprendido.

La fenomenología política de inspiración lefortiana nos invita, así, a ser sensibles a las mutaciones de la democracia contemporánea, como diría Isidoro Cheresky en un texto ya citado, a ir más allá de las quejas o celebraciones de la crisis de la representación política para preguntarnos por los sentidos abiertos por las lógicas de auto-representación y de

\footnotetext{
${ }^{3}$ En respuesta a un muy interesante planteo hecho por Enrique Peruzzotti (en un artículo inédito que será parte de un volumen especial de la revista Constellations), en el que las versiones republicana/liberal y populista de la democracia propone sean vistas como posiciones que enfatizan, alternativamente, la dimensión constituida o constituyente de la vida política.

${ }^{4}$ Isidoro Cheresky, El nuevo rostro de la democracia. Buenos Aires: FCE, 2015. P. 81.
} 
relevancia continua de los estados de opinión. Esto abre las puertas, de todos modos, a la posibilidad de que las mutaciones que tengan y tienen lugar no sean, siempre y necesariamente, "mutaciones de la democracia", sino que nos obliguen a mantenernos atentos a la forma política general, a la gestalt que organiza y establece la matriz general de la vida colectiva; y, eventualmente, a la posibilidad de que ésta, bajo ciertas circunstancias, deje de ser democrática - y creo que hay suficiente prueba de que las transformaciones ocurridas en Estados Unidos, por ejemplo, a partir del 11 de septiembre de 2001 abrieron nuevos interrogantes que bien pueden ser aquellos de la mutación de la forma democrática misma.

Es precisamente con relación a la posibilidad de capturar con precisión las transformaciones ocurridas luego del 11 de septiembre de 2001 que percibí la necesidad de reelaborar ciertas nociones del pensamiento de Lefort. En particular, lo que provocó en mí perplejidad fue la obvia tensión que existía durante los años de la administración Bush (pero también durante Obama, y por supuesto mucho más hoy, bajo la presidencia de Donald Trump) entre la relevancia que adquiría la descripción lefortiana de la democracia y su crítica al totalitarismo y la incapacidad de aplicar sus categorías para la descripción de aquello que aparecía - definitivamente la sociedad norteamericana no estaba deviniendo “totalitaria" pero, ¿era todavía plenamente democrática en el sentido de Lefort?

En particular, lo que provocaba - y provoca — perplejidad es la manera en la que en cuatro de las dimensiones centrales de la descripción fenomenológica que Lefort ofrece de lo que llamaba forma de sociedad democrática los Estados Unidos parecían y parecerían estar implosionando: 1) cada vez más, la sociedad norteamericana y sus principales actores políticos parecen decididos a ya no tolerar una imagen de la sociedad como dividida, lo que los llevaba y lleva a mostrar una creciente fascinación con la idea del Pueblo-Uno, hoy bajo la candidatura primero y la presidencia luego de Donald Trump, decididamente materializadas en un Pueblo-Uno identitariamente asociado a una percepción etnonacionalista del "cuerpo social"; 2) el lugar del poder parece estar siendo re-ocupado y re-encarnado como consecuencia de la reconquista plutocrática de la totalidad del proceso político y de los mecanismos estatales; 3) el hecho de que, como insistía Dick Cheney con frecuencia, "el 11 de septiembre lo había cambiado todo", significaba y significa que los Estados Unidos han caído presos de la fantasía de la seguridad total, de una certeza de seguridad que empuja a la sociedad a un creciente rechazo a la incertidumbre democrática y en la dirección de una legitimación de la desaparición de personas, la tortura y, más recientemente, el asesinato estatal global mediante el uso de drones o misiles como políticas públicas que llegaron para quedarse; y, finalmente, 4) que la ya mencionada atracción por la idea del Pueblo-Uno también se manifiesta (como puede verse con la fascinación el movimiento encabezado por Donald Trump en el Partido Republicana) en la obsesión con la necesidad de "purgar" a los inmigrantes sin papeles (fundamentalmente a los 
latinoamericanos, y estamos hablando de cerca de 12 millones de personas...) de una noción orgánica de "cuerpo político" racializada y xenófoba.

El hecho de que todo esto está ocurriendo, pero que de todos modos sigue pareciendo imposible, o al menos no suficientemente preciso, usar la tipología de formas de sociedad lefortiana - ¿está Estados Unidos convirtiendose en un régimen teológicopolítico? ¿en uno totalitario? Es todavía difícil encontrar en estas categorías el vocabulario adecuado para comprender lo que aparece — me llevó a la siguiente sugerencia con respecto a su noción de regímenes políticos.

\section{Una tipología de regímenes políticos}

Pasaré ahora a la formulación de esta lectura correctiva de la tipología de formas de sociedad ofrecida por Lefort. Para plantear esta lectura modificada, me serviré de algunos aspectos propios de los pensamientos de Jacques Rancière y Maurice Merleau-Ponty. Esta modificación-alteración me permitirá luego concebir uno de los sentidos que Lefort da a las formas de sociedad teológico-política, democrático-moderna y totalitaria en términos de regímenes de prácticas e instituciones, posiciones sociales y horizontes interpretativos, sucesivamente disponibles, sucesivamente advenidos y sedimentados, capaces de ser eventualmente, pero también contingentemente, reactivados. En una entrevista realizada para la edición en inglés de su Le partage du sensible, Rancière, hablando de sus regímenes estéticos, planteó lo siguiente:

La visibilidad de una forma de expresión como forma artística depende de un régimen de percepción e inteligibilidad históricamente constituido. Esto no quiere decir que ésta deviene invisible con la emergencia de un nuevo régimen... Enunciaciones o formas de expresión indudablemente dependen de sistemas de posibilidades históricamente constituidos que determinan formas de visibilidad o criterios de evaluación, pero esto no quiere decir que uno salta de un sistema a otro de tal modo que la posibilidad de un nuevo sistema coincide con la imposibilidad del sistema anterior, de modo que, el régimen estético del arte, por ejemplo, es un sistema de posibilidades que es constituido históricamente pero que no logra abolir al régimen representativo, que era previamente el dominante. En cierto punto del 
tiempo, varios regímenes coexisten y se entrelazan en las obras mismas. $^{5}$

Para comprender la forma en la que el pensamiento de Lefort se entrelaza con esta concepción estético-política es necesario aludir brevemente al origen merleau-pontiano de la obra del primero. Sintéticamente, podría decirse que el trabajo filosófico de MerleauPonty se desarrolló a lo largo del desplazamiento de la noción de sujeto encarnado a la de elemento general, de la idea de cuerpo a la idea de carne. ${ }^{6}$ Este último concepto, entendido como elemento en el sentido que los griegos daban al término - tierra, fuego, aire - supone que la carne es aquel elemento que no llegó a ser completamente teorizado por la tradición occidental. En este contexto, el pensamiento lefortiano asumió, siguiendo a Merleau-Ponty, que la carne es no sólo el elemento del que están hechos los cuerpos individuales, tanto humanos como animales, sino también aquel del que está hecha la inter-corporalidad de la vida colectiva. Así es como nace, tanto en Merleau-Ponty como en Lefort, la idea de la "carne de lo social", de la sociedad como elemento. Y, como es evidente, no hay elemento que exista sin forma. Nada que sea a la manera de la carne puede serlo careciendo de toda configuración; como nada es meramente a la manera de la tierra, el fuego o el aire. Las formas políticas en Lefort - las formas de sociedad - son concepciones generales de estilos de configuración de la sociedad.

En este marco, la forma teológico-política es aquella que asume que la configuración de la carne de lo social se da a través de una fuente trascendente, divina, extra-social, y de su representante terrenal en la figura del rey. A la inversa, la forma que yo llamaré epistémico-política - pero que Lefort llamó totalitaria - ya no concibe la configuración de lo social como trascendente sino, por el contrario, como resultado de una inmanencia radical; como resultado de la localización de un punto de vista interior a la sociedad que es capaz de convertir a la misma en transparente ante sí; como resultado de lograr una reversibilidad total entre la sociedad como vidente y la sociedad como visible. La forma que propongo llamar estético-política, finalmente, asume el fracaso en última instancia de la reversibilidad de lo social - la carne de lo social, como toda carne, es tanto vidente como visible, pero a pesar de ser vidente-visible no logra nunca una reconciliación absoluta de esta bi-dimensionalidad. A partir de este punto de partida, Lefort ofreció una interpretación a la vez histórica y filosófica de las tres formas de sociedad arriba mencionadas, todas ellas articuladas cronológica, pero sobre todo genealógicamente, a partir del modelo cristológico de la pre-modernidad europea, pasando por la moderna

\footnotetext{
${ }^{5}$ Jacques Rancière. The Politics of Aesthetics. New York: Continuum, 2006, p. 50. La traducción es mía. La versión francesa es Jacques Rancière. Le partage du sensible. Esthétique et politique. Paris: La fabrique, 2000.

${ }^{6}$ Ver, en particular, Maurice Merleau-Ponty. Le visible et l'invisible. Paris: Gallimard, 1964.
} 
disolución de las marcas de certidumbre y finalmente inaugurando la reacción totalitaria ante ellas.

Se me perdonará lo sintético de esta génesis y descripción del modelo lefortiano, pero querría pasar rápidamente a la identificación de una sutil pero, quizás, importante limitación que quiero atribuir a este modelo: esta limitación está asociada a su teorización de tales formas políticas como cuasi-totalidades gestálticas mutuamente excluyentes. Sin pretender negar la existencia de configuraciones o constelaciones identificables de prácticas e instituciones, articulaciones de relaciones sociales y principios generativos dominantes de la vida colectiva, configuraciones que, en efecto, hacen primar ciertas prácticas por sobre otras, ciertas instituciones por sobre otras, etc., querría sugerir, como anticipé, que los regímenes lefortianos deberían más bien verse a la manera de los regímenes estéticos rancierianos, es decir, como conjuntos de visibilidades e invisibilidades, de diferentes principios generativos, sobreimpuestos y en competencia los unos con los otros. Así, el modelo lefortiano modificado nos ofrecería una tipología de horizontes de configuración de la vida colectiva, de regímenes de visibilidades e invisibilidades, de lo pensable e impensable, pero en el sentido rancieriano de los regímenes estéticos, también tripartito: 1) el régimen teológico-político, 2) el estético-político, y 3) el epistemológico-político.

De todas maneras, mientras que propongo cambiar el sentido de la noción de regímenes para así permitirles a éstos permanecer en conflicto y coexistencia los unos con los otros en todo tiempo y lugar, también sugiero preservar la idea de formas de sociedad tal como Lefort la concibió. De este modo, al separar el uso indistinto de las nociones de "régimen" y "forma de sociedad" en dos categorías diferentes se habilita la posibilidad de comprender dos dimensiones diferenciables de la vida colectiva. Por un lado, se permite así la identificación de una situación aparentemente paradójica de constelaciones de prácticas, instituciones y posiciones sociales, de visibilidades e invisibilidades, de formas de delimitación de lo pensable y lo impensable, contemporáneas y en conflicto las unas con las otras. Por otro lado, se propone la preservación del poder iluminador de la noción de formas de sociedad, noción que nos permite seguir siendo capaces de, a su vez, identificar regularidades en esta coexistencia y conflicto de regímenes, regularidades que se constituyen en regímenes dominantes durante determinados períodos históricos y en determinados espacios sociales.

Permítanme dar un par de ejemplos: La alianza del catolicismo y la oposición democrática en contra de los regímenes comunistas de Europa del Este podría describirse como una alianza anti-epistémica. La del cristianismo político y las epistemologías políticas del estado mínimo en el Partido Republicano de los Estados Unidos de hoy, al igual que la misma alianza en los terrorismos de estado del Cono Sur de ayer, como alianzas teológico y epistémico-políticas contra la pluralidad del régimen estético de la política. Las teologías y las epistemologías políticas son diametralmente opuestas porque surgen de posturas 
mutuamente incompatibles, inspiradas en justificaciones divinas o científico-filosóficas del monopolio de la determinación de lo pensable e impensable, de lo visible y lo invisible; en la práctica, de todos modos, comparten su carácter anti-estético - es decir, anti-pluralista.

Para resumir entonces:

El régimen teológico de la política funda sus pretensiones de legitimidad en una fuente externa, constituyente de unidad de lo social o del pueblo. De este modo, el régimen teológico-político no necesita ser propiamente teológico, simplemente requiere de la fascinación con el gesto de la encarnación, necesitar estar cautivado por la posibilidad de que el enigma de la voluntad divina o del pueblo pueda de algún modo ser materializado y representado plenamente en el corazón de la sociedad.

El régimen epistémico de la política, por otro lado, niega la existencia de dicha fuente externa, constituyente, de la sociedad y por lo tanto supone que ésta es orgánica y transparente ante sí misma - por supuesto, si no le permitimos a la contingencia y la polifonía de la política democrática bañar de opacidad a lo social — y, por lo tanto, espontáneamente organizada si los procesos que son sabidos como centrales a dicho organismo social no son molestados u obstaculizados por elementos "externos" a su funcionamiento.

Estos regímenes antagónicos de la política — el teológico y el epistémico — suelen enfrentarse fuertemente; pero esto no siempre ocurre, ya que tampoco es inusual para ellos encontrar un suelo común en su rechazo a un tercer régimen, uno que es visto desde estas perspectivas como inaceptablemente ambivalente y desestabilizador: el régimen estético de la política.

El régimen estético de la política, finalmente, es el horizonte de configuración de la vida colectiva cuyo gesto central es el de la institucionalización de la indeterminación esto es, la institucionalización de la aceptación abierta y pluriperspectiva de que no hay decisión final ni solución definitiva al enigma de la vida social.

Instituciones características de los regímenes teológicos y epistémicos de la política son, por ejemplo, la pena de muerte y la doctrina de la guerra preventiva (la guerra agresiva u ofensiva). Instituciones características del régimen estético-político, por otro lado, son las elecciones competitivas, la presunción de inocencia y, por supuesto, la prohibición de la guerra ofensiva y la pena de muerte.

\section{Verdad deseada}

Como anticipé más arriba al indicar el origen merleau-pontyano del pensamiento de Lefort, querría recordar que fue precisamente Merleau-Ponty quién con más claridad y más tempranamente se avocó a la interrogación del carácter estético de la política. Para sugerir ciertos peligros que, lamentablemente, dominan hoy la vida política latinoamericana, 
permítaseme entonces cerrar revisitando brevemente el modo en que Merleau-Ponty capturó el momento en que las bases epistémicas del comunismo eran reemplazadas por el decisionismo voluntarista de lo que en ese momento este autor describió como el "ultrabolchevismo" sartreano. ${ }^{7}$

El fracaso de la dialéctica, que Merleau-Ponty en ese momento asumió como un hecho, era el fracaso del punto de vista epistémico-político del marxismo, su pretensión de surgir del conocimiento más completo y profundo de lo social y de su devenir histórico. Este punto de partida también era el de Sartre. El problema no provenía entonces del diagnóstico de la crisis de la dialéctica sino de la frustración cuasi-religiosa con la que Sartre respondió a la misma - y de lo que éste hizo con ella, que para Merleau-Ponty no fue más que reemplazar la espontaneidad histórica del proletariado como sujeto cognoscible por la filosofía y la ciencia del marxismo con la voluntad decisionista del partido que lo constituye radicalmente al decir representarlo. Para Merleau-Ponty, el paso del saber a la voluntad, de la razón a la decisión, no fue más que un giro idealista ante el fracaso del "realismo" materialista del Marxismo. Fue el paso, en definitiva, de una postura epistémico-política a una teológico-política - y lo que Merleau-Ponty opuso a ambas fue una mirada decididamente estético-política.

En la obra de Merleau-Ponty, tan influyente en Lefort, puede encontrarse - muy claramente formulada - una teoría de la acción que no es ni decisionista ni racionalista. Lo que se lee en Las aventuras de la dialéctica en particular es, además de una teoría estéticopolítica de la acción, el esbozo de un régimen particular de configuración de la vida colectiva que acoge la pluralidad y la autonomía; o, como él decía, la oposición y la libertad. ¿Sabíamos ya cuál era ese régimen? Solo provisionalmente. Sabíamos, de todos modos, cuáles no lo eran: el capitalismo como sistema de explotación económica y el comunismo como sistema de dominación política.

Para Merleau-Ponty, la hipótesis más promisoria para la formulación positiva del régimen deseado partía de la posibilidad de desvincular a la democracia como régimen político en el sentido de horizonte - y que él llamaba democracia parlamentaria, para subrayar su carácter pluralista - de aquellas asociaciones dogmáticas que pretenden reducirla, por un lado, a mero instrumento político de la burguesía - algo que hacen tanto Schmitt como los diversos marxismos - o, por el otro, a mero estadio táctico en la lucha de clases cuando todavía las relaciones de fuerzas no permiten la instauración de la dictadura del proletariado. Del impasse irrecuperable al que había llegado la dialéctica objetiva, Merleau-Ponty sugirió entonces que Sartre forzaba la salida hacia un voluntarismo decisionista constituyente - en el sentido planteado más arriba, en oposición a "instituyente" - que retenía la idea, pero disociada de la praxis dialéctica, de un proletariado

${ }^{7}$ Ver Maurice Merleau-Ponty. Les aventures de la dialectique. Paris: Gallimard, 2000, pp. 135-280. 
y sus representantes como capaces de construir una sociedad sin clases. Ante esta salida voluntarista, Merleau-Ponty, mucho más modestamente, sugirió que el único punto de partida aceptable era el de un régimen que acogiese la oposición - la verdad sobre-reflexiva, en sus palabras de Lo visible y lo invisible - y la libertad - una dialéctica circular, sin telos, una hiperdialéctica, en sus palabras también de Lo visible y lo invisible. Y para él, el único régimen de este tipo del que teníamos conocimiento, al momento en que se propuso "hablar filosóficamente de política", ${ }^{8}$ fue lo que llamó democracia parlamentaria. Diagnóstico que llevó a Merleau-Ponty a formular su idea de política y de acción:

Si hay acción, es necesario evocar información, hechos, una discusión [...] argumentos, una preferencia dada a esto por sobre aquello, en breve, lo probable, lo cual Sartre no puede ver, porque él lo ve como un racionalista y le parece una disminución de nuestra certeza. [Pero] lo probable es otro nombre de lo real, es la modalidad de lo que existe [...]. No hay acción digna del nombre que sea "acción pura". La acción pura, el partido "unánime", son la acción y el partido vistos desde el exterior... La acción pura, llevada al límite, es el suicidio o la muerte. ${ }^{9}$

En la mirada estético-política de Merleau-Ponty, la acción nunca es "pura" nunca es constituyente - el devenir político nunca se acerca, ni siquiera mínimamente, al fin de la historia; ni puede introducir en la realidad un orden apasionadamente deseado o filosóficamente imaginado que no surja del conflicto de opiniones y de fuerzas, de tradiciones y de expresiones creadoras, de estructuras y de prácticas al interior de la carne de lo social que se propone transformar. No hay respuesta a la pregunta sobre qué viene de las cosas y qué de la acción, sobre qué estaba ya allí y qué es novedad pura. Nuestra única certeza es que ningún extremo de la ecuación existe sin el otro.

En el horizonte de configuración de la vida colectiva que llamo régimen estéticopolítico, esta irreductibilidad del carácter entrelazado de las dimensiones instituyentes e instituidas de la vida social se extiende a las cuestiones del poder y la representación, y a las del sentido de la definición misma del pueblo o de sus actores colectivos. En los regímenes epistémicos y teológicos de la política, por otro lado, "el saber teórico que solo el partido posee" en el primero, o el "no-saber absoluto" del voluntarismo del segundo, llevan

\footnotetext{
8 Merleau-Ponty comienza Les aventures de la dialectique diciendo: "Para tratar los problemas que tocamos aquí hace falta una filosofía de la historia y del espíritu. Pero sería hacer uso de un falso rigor pretender contar con principios perfectamente elaborados para hablar filosóficamente de política. Ante la exigencia de los acontecimientos reconocemos aquello que nos resulta inaceptable y es esta experiencia interpretada la que deviene filosofía". Ibid., p. 9.

${ }^{9}$ Ibid., pp. 164-6.
} 
consigo la tentación de la acción pura - y, como dice Merleau-Ponty: cuando "los hombres desean crear cosas ex nibilo, allí es cuando lo sobrenatural reaparece". ${ }^{10}$

Es verdad que Merleau-Ponty no investigó explícitamente las implicancias notoriamente schmitteanas del ultradecisionismo sartreano. Lo que sí hizo, de todos modos, fue comprender cabalmente en su momento de origen las consecuencias teológicopolíticas de un marxismo al que la contingencia obligó a abandonar el postulado epistémico de un conocimiento objetivo total, sin por esa razón posponer el deseo de convertir en realidad su "verdad" filosófica. Pero "la certeza de ser el portador de la verdad es vertiginosa [y ésos] son los frutos envenenados de la verdad deseada: ella autoriza a avanzar contra todas las apariencias; ella es, en sí misma, locura". ${ }^{11}$

Para concluir, permítaseme indicar que es a la manera de la verdad deseada que reaparece en nuestros días una de las formas más comunes del régimen teológico de la política: el populismo. Esta respuesta reacciona tanto al colapso del despliegue objetivo de la historia postulado por la epistemología política del marxismo como a la crisis de las oligarquías neoliberales a escala global del siglo XXI. Las otras versiones de teologías políticas contemporáneas son ya más convencionales, por supuesto: la persistencia y recurrencia de las teologías políticas cristianas en occidente, y las múltiples teologías políticas no-secularizadas de la escena global.

La verdad deseada del voluntarismo postmarxista que encarnó primero Sartre, quiero concluir, se convirtió en dominante en la política revolucionaria latinoamericana que siguió al éxito de la revolución cubana: la izquierda abandonó la narrativa epistemocéntrica y alternó de allí en más entre una teología política secularizada de la violencia revolucionaria - bajo la forma del foquismo o el guevarismo - y una teología política seculariza de la voluntad popular soberana - la izquierda populista. Por supuesto que éstas no fueron las únicas respuestas al colapso de la epistemología política del marxismo. Muy por el contrario, la principal alternativa surgida fue aquella que puede intuirse tanto en el "hablar filosóficamente de política" del propio Merleau-Ponty como en la inauguración de la izquierda democrática a las que me referí en el primer apartado — tanto la postestructuralista gramsciana como la fenomenológica, ambas estético-políticas.

De todos modos, la verdad deseada, la acción voluntarista, cuando todavía entra en competencia conflictiva con la hegemonía del régimen estético de la política, tiende a convertirse, como decía Merleau-Ponty, en suicida o asesina - tanto metafórica como literalmente. Literalmente, en la forma de una violencia política que busca imponer a sangre y fuego su verdad filosófica. Metafóricamente, a la manera de actores políticos cuyas

\footnotetext{
${ }^{10}$ Ibid., pp. 211.

${ }^{11}$ Ibid., p. 182-3.
} 
acciones voluntaristas generan las condiciones para su propia extinción y/o buscan demasiado proactivamente la de sus adversarios.

Es más bien en su forma metafórica que la verdad deseada aparece ante nuestros ojos en algunas prácticas y discursos de la izquierda latinoamericana de hoy — pero lo hacen en una región mayormente hegemonizada por el régimen estético de la política, es decir, por un horizonte de configuración de la vida colectiva que no se caracteriza por ofrecer las condiciones discursivas, prácticas e institucionales proclives para la consolidación de proyectos políticos teológicos (secularizados o no) o epistémicos (marxistas o neoliberales). Esto no debería ser causa de relajación, de todos modos, ya que tanto los raramente metafóricos defensores de la verdad epistémica del capitalismo antiregulatorio como las tentaciones teológico-políticas de la izquierda populista y/o revolucionaria siempre pueden encontrarse -como ya lo hicieron trágicamente en el pasado - en ese lugar anti-estético más allá de todo pluralismo en el que sólo la violencia logra prevalecer.

\section{Referências bibliográficas}

CHERESKY, I. El nuevo rostro de la democracia. Buenos Aires: FCE, 2015.

MERLEAU-PONTY, M. Les aventures de la dialectique. Paris: Gallimard, 2000. Le visible et l'invisible. Paris: Gallimard, 1964.

RANCIÈRE, J. The Politics of Aesthetics. New York: Continuum, 2006.

. Le partage du sensible. Esthétique et politique. Paris: La fabrique, 2000. 